\title{
Continuous monitoring of summer surface water vapor isotopic composition above the Greenland Ice Sheet
}

\author{
H. C. Steen-Larsen ${ }^{1,2}$, S. J. Johnsen ${ }^{1}$, V. Masson-Delmotte ${ }^{3}$, B. Stenni ${ }^{4}$, C. Risi ${ }^{5}$, H. Sodemann ${ }^{6}$, D. Balslev-Clausen ${ }^{1}$, \\ T. Blunier ${ }^{1}$, D. Dahl-Jensen ${ }^{1}$, M. D. Ellehøj ${ }^{1}$, S. Falourd ${ }^{3}$, A. Grindsted ${ }^{1}$, V. Gkinis ${ }^{1}$, J. Jouzel ${ }^{3}$, T. Popp ${ }^{1}$, S. Sheldon ${ }^{1}$, \\ S. B. Simonsen ${ }^{1,7}$, J. Sjolte ${ }^{1,8}$, J. P. Steffensen ${ }^{1}$, P. Sperlich ${ }^{1,9}$, A. E. Sveinbjörnsdóttir ${ }^{10}$, B. M. Vinther ${ }^{1}$, and \\ J. W. C. White ${ }^{11}$ \\ ${ }^{1}$ Centre for Ice and Climate, Niels Bohr Institute, University of Copenhagen, Denmark \\ ${ }^{2}$ Cooperative Institute for Research in Environmental Sciences, University of Colorado, Boulder, USA \\ ${ }^{3}$ Laboratoire des Sciences du Climat et de l'Environnement, UMR CEA-CNRS-UVSQ/IPSL 8212, Gif-sur-Yvette, France \\ ${ }^{4}$ Department of Mathematics and Geosciences, Environmental and Marine Sciences, University of Trieste, Italy \\ ${ }^{5}$ Laboratoire de Météorologie Dynamique, Jussieu, Paris, France \\ ${ }^{6} \mathrm{ETH}$, Institute for Atmospheric and Climate Science, ETH Zürich, Switzerland \\ ${ }^{7}$ Danish Climate Center, DMI, Lyngbyvejen 100, 2100 Copenhagen, Denmark \\ ${ }^{8}$ Department of Geology, Lund University, Sölvegatan 12, SE-22362 Lund, Sweden \\ ${ }^{9}$ Max-Planck-Institute for Biogeochemistry, 07745 Jena, Germany \\ ${ }^{10}$ Institute of Science, University of Reykjavik, Dunhaga 3, Reykjavik 107, Iceland \\ ${ }^{11}$ Institute of Arctic and Alpine Research, Campus Box 450, University of Colorado, Boulder, CO 80309, USA
}

Correspondence to: H. C. Steen-Larsen (hanschr@gfy.ku.dk)

Received: 25 October 2012 - Published in Atmos. Chem. Phys. Discuss.: 14 January 2013

Revised: 15 March 2013 - Accepted: 5 April 2013 - Published: 13 May 2013

\begin{abstract}
We present here surface water vapor isotopic measurements conducted from June to August 2010 at the NEEM (North Greenland Eemian Drilling Project) camp, NW Greenland $\left(77.45^{\circ} \mathrm{N}, 51.05^{\circ} \mathrm{W}, 2484 \mathrm{~m}\right.$ a.s.l.). Measurements were conducted at 9 different heights from $0.1 \mathrm{~m}$ to $13.5 \mathrm{~m}$ above the snow surface using two different types of cavity-enhanced near-infrared absorption spectroscopy analyzers. For each instrument specific protocols were developed for calibration and drift corrections. The intercomparison of corrected results from different instruments reveals excellent reproducibility, stability, and precision with a standard deviations of $\sim 0.23 \%$ o for $\delta^{18} \mathrm{O}$ and $\sim 1.4 \%$ o for $\delta$ D. Diurnal and intraseasonal variations show strong relationships between changes in local surface humidity and water vapor isotopic composition, and with local and synoptic weather conditions. This variability probably results from the interplay between local moisture fluxes, linked with firn-air exchanges, boundary layer dynamics, and large-scale moisture advection. Particularly remarkable are several episodes characterized by high $(>40 \%$ ) surface water vapor deu-
\end{abstract}

terium excess. Air mass back-trajectory calculations from atmospheric analyses and water tagging in the LMDZiso (Laboratory of Meteorology Dynamics Zoom-isotopic) atmospheric model reveal that these events are associated with predominant Arctic air mass origin. The analysis suggests that high deuterium excess levels are a result of strong kinetic fractionation during evaporation at the sea-ice margin.

\section{Introduction}

Water stable isotopes from Greenland ice cores provide highly resolved, well-dated climate information (e.g., Svensson et al., 2006). The archived climate signal is however an integrated signal of the precipitation isotopic composition, which itself is controlled by variations in moisture origin and condensation history (Sodemann et al., 2008; Masson-Delmotte et al., 2005; Johnsen et al., 1989; Fisher, 1992, 1991). The initial snowfall isotopic composition signal is subject to post-deposition processes linked with wind 
scouring, exchange between top firn layer and atmosphere, and interstitial diffusion (Johnsen, 1977; Johnsen et al., 2000; Simonsen et al., 2011; Kavanaugh and Cuffey, 2003; Fisher, 1992, 1991; Koerner and Fisher, 1990; Fisher, 1990). Classically, the interpretation of ice core data relies on theoretical calculations, using Rayleigh distillation models or atmospheric general circulation models equipped with water stable isotopes (Hoffmann et al., 2000; Joussaume et al., 1984; Johnsen et al., 1989; Ciais and Jouzel, 1994), to explore the climatic controls on precipitation isotopic composition. However key parameterizations of the water and vapor isotope cycles in these models remain associated with significant uncertainty - from the evaporation in the source region (Merlivat and Jouzel, 1979), through the presence of mixed phase clouds (Ciais and Jouzel, 1994), to the formation of snow crystals under super saturation (Jouzel and Merlivat, 1984). To validate some of the assumptions associated with these parameterizations, models have been compared with global datasets of precipitation isotopic composition and Greenland ice core records (Sjolte et al., 2011). Only very limited datasets of direct Greenland snowfall measurements are available (Grootes and Stuiver, 1997; Steen-Larsen et al., 2011), and, so far, atmospheric models equipped with water stable isotopes have not been validated against these data.

The isotopic composition of atmospheric water vapor represents an intermediate product in the hydrological cycle between the source evaporation and cloud condensation. Combined with precipitation data, measurements of water vapor isotopic composition have therefore the potential of enhancing our knowledge of the processes governing the hydrological cycle. Indeed, large-scale advection, vertical mixing in the atmospheric boundary layer, cloud microphysics, and exchange between the atmosphere and the snow surface do affect water vapor and precipitation isotopic composition. Direct isotopic water vapor measurements in the atmosphere are therefore needed. As the use of satellite remote sensing of water vapor isotopic composition is currently not available for high latitudes (Worden et al., 2006; Frankenberg et al., 2009), in situ observations are essential. So far, only few studies have carried out long-term monitoring of the water vapor in the atmosphere (Jacob and Sonntag, 1991; Angert et al., 2008) or analyzed the water vapor isotopic composition above the Greenland Ice Sheet (Grootes and Stuiver, 1997; Steen-Larsen et al., 2011).

We briefly review here existing Arctic water vapor isotope datasets. The earliest water vapor studies showed that the isotopic composition of the surface vapor was strongly affected by changes in air mass origin as well as by the history of precipitation from the air mass prior to collection (Craig and Gordon, 1965; Dansgaard, 1954). However, due to the labor intensity related to collecting the vapor samples using a cold trap, such studies have remained extremely limited especially for the Arctic.
High d-excess (d-excess $\left.=\delta \mathrm{D}-8 \times \delta^{18} \mathrm{O}\right)$ levels were observed in moisture originating from the Arctic by Kurita (2011) during a cruise in the Bering Strait in September and October 2008 where 140 samples were collected with a 6 hourly resolution. These high d-excess values were attributed to a strong kinetic fractionation caused by dry polar air masses transported above the open sea near the edge of the sea ice. Similar effect of kinetic fractionation on d-excess was previously observed in the eastern Mediterranean (Gat et al., 2003; Angert et al., 2008). This kinetic fractionation effect arises in the skin layer where molecular diffusion is dominant. The humidity gradient in the skin layer affects the relative fractionation of $\mathrm{HD}^{16} \mathrm{O}$ and $\mathrm{H}_{2}^{18} \mathrm{O}$ due to their difference in molecular diffusivities (Merlivat and Jouzel, 1979; Fisher, 1991).

From samples collected twice per day by Grootes and Stuiver (1997) during the summer field season of 1990 at GISP2 (Greenland Ice Sheet Project 2), central Greenland, very high correlation was found between the variability of $\delta^{18} \mathrm{O}$ of the snow and frost, and the $\delta^{18} \mathrm{O}$ of the atmospheric water vapor samples. A similar conclusion was reached based on 29 atmospheric water vapor samples collected morning and evening during the 2008 field season at the North Greenland Eemian Drilling Project (NEEM), NW Greenland (SteenLarsen et al., 2011). They showed $\delta^{18} \mathrm{O}$ of the vapor to be lagging variations in precipitation $\delta^{18} \mathrm{O}$ during snowfall events. Both d-excess measurements of these samples (Steen-Larsen et al., 2011) and ${ }^{17} \mathrm{O}$-excess measurements conducted on a subset of these samples (Landais et al., 2011) indicated that the surface water vapor predominantly is in isotopic equilibrium with the snow surface. Still, unknown factors exist in relation to formation and post-depositional processes of the isotopic composition of the snow surface. Specifically, the magnitude of the interaction between the snow surface and the water vapor above the snow surface as well as the cloud condensation height governing the relation between temperature and isotopic composition of the precipitation.

Cavity-enhanced absorption spectroscopy has recently allowed continuous in situ measurements of atmospheric water vapor isotopic composition (Kerstel et al., 1999; Lee et al., 2005). In this study, we take advantage of different types of commercial laser instruments recently developed (Crosson et al., 2002; Baer et al., 2002). By deploying two different laser instruments and comparing the independently produced data records we are directly able to evaluate the accuracy and precision. We have implemented specific calibration protocols to correct for instrumental drifts and produce results against international standard waters. To enhance the interpretation of ice core records, we have conducted our surface water vapor monitoring program at the NEEM deep ice core drilling camp, NW Greenland, during the 2010 summer field season.

In Sect. 2, we describe the methods applied (NEEM site characteristics, field setup, calibration protocol, back trajectory analyses and modeling tools). In Sect. 3, we quantify the precision and accuracy of the isotopic vapor measurements, 
describe the observed isotopic variability and combine atmospheric modeling with our observations to investigate the large-scale drivers of day-to-day isotopic variability.

\section{Material and methods}

Throughout the paper, we will use the $\delta$ notation (Dansgaard, 1964). The definition of the $\delta$ notation is based on the relative composition $(R)$ of the two stable water isotopes ${ }^{1} \mathrm{H}^{2} \mathrm{H}^{16} \mathrm{O}$ and ${ }^{1} \mathrm{H}_{2}^{18} \mathrm{O}$ compared to ${ }^{1} \mathrm{H}_{2}^{16} \mathrm{O}$, and is given by

$\delta^{*}=\left(R_{\text {Sample }} / R_{\mathrm{V}-\mathrm{SMOW}}-1\right) \times 1000[\%]$,

where $\delta^{*}$ represent either $\delta^{18} \mathrm{O}$ or $\delta \mathrm{D}$, and $R_{\mathrm{V} \text {-SMOW }}$ is the relative composition of the V-SMOW standard, Vienna Standard Mean Ocean Water.

\subsection{NEEM site characteristics}

An international deep drilling program has been conducted at NEEM, NW Greenland $\left(77.45^{\circ} \mathrm{N}, 51.05^{\circ} \mathrm{W}, 2484 \mathrm{~m}\right.$ a.s.l.), from 2007 to 2012, providing climatic and glaciological information back to the last interglacial period. Specific monitoring efforts have been dedicated to water stable isotopes in pits, surface snow, precipitation and water vapor (SteenLarsen et al., 2011). Air temperature and relative humidity (postcorrected with respect to ice) were measured using Campbell Sci. HMP45C $( \pm 0.1 \mathrm{~K}$ and $\pm 5 \%<90 \% \mathrm{RH}$, relative humidity, and $\pm 10 \%>90 \% \mathrm{RH}$ ), wind direction and speed using an R.M. Young propeller-type vane $\left( \pm 5^{\circ}\right.$ and $\pm 0.1 \mathrm{~m} \mathrm{~s}^{-1}$ ), and station pressure using Vaisala PTB101B $( \pm 0.1 \mathrm{mb})$ (Steffen and Box, 2001; Steffen et al., 1996). The estimated mean summer (JJA) temperature at NEEM is $\sim-11 \pm 5^{\circ} \mathrm{C}(1 \sigma$ based on $2006-2011)$, and the annual mean accumulation rate from 1964 to 2005 is estimated at $20 \mathrm{~cm} \mathrm{a}^{-1}$ (water equiv.), with a large fraction (between 2.5 and 4.5) of precipitation occurring in JJA compared to DJF (Steen-Larsen et al., 2011). July of 2010, which is a particular focus of this paper was characterized by a high and stable AO (Arctic Oscillation) index of $\sim 0.42$ compared to a climatologically mean of $\sim-0.11 \pm 0.43$. The mean of the variability of the AO July index is $\sim 0.63 \pm 0.25$ compared to the 2010 variability of the AO July index of $\sim 0.40$.

\subsection{Atmospheric modeling}

In order to characterize the long-range air mass advection to the NEEM site back-trajectory calculations using the FLEXTRA (FLEXible TRAjectories) model (Stohl and Seibert, 1998; Stohl et al., 1995) have been conducted for the period of the measurement campaign. The advection field is based on 6 hourly ECMWF (European Centre for MediumRange Weather Forecasts) meteorological analysis data supplemented by $3 \mathrm{~h}$ forecast data. Seven-day back-trajectories were initiated at 2500 and $3000 \mathrm{~m}$ a.s.l every $6 \mathrm{~h}$ over the
NEEM site (altitude in the EMCWF model $2380 \mathrm{~m}$ a.s.l). Depending on the meteorological situation, air mass trajectories could differ in shape depending on initial altitude, but at most times the initial flow direction was similar. We therefore only show results from the trajectories started at $2500 \mathrm{~m}$ a.s.1.

To support the interpretation of the isotopic water vapor data, we use outputs from a general circulation model, LMDZiso (Laboratory of Meteorology Dynamics Zoomisotopic; Hourdin et al., 2006), enabled with water isotopes (Risi et al., 2010a, b). The model is used with a resolution of $2.5^{\circ}$ in latitude, $3.75^{\circ}$ in longitude and 19 vertical levels. The model is forced by the monthly sea surface temperature from the NCEP (National Centers for Environmental Prediction) reanalysis (Kalnay et al., 1996; Kanamitsu et al., 2002). Simulations using sea-ice concentration from Nimbus-7 SSMR (Scanning Multichannel Microwave Radiometer) and DMSP SSM/I (Defense Meteorological Satellite Program Special Sensor Microwave/Imager) passive microwave data (Fetterer et al., 2002) led to little change compared to standard forcing used by LMDZiso (not shown). The simulated threedimensional fields of horizontal winds are nudged towards those of the ECMWF operational analysis, so that the model can capture weather patterns at the daily scale. We use the simulated water vapor isotopic composition from the lowest model level at the NEEM grid point to compare with our observations. To investigate the relationship between the inflow of Arctic moisture and the water vapor isotopic composition, we ran LMDZiso with the water tagging functionality (Risi et al., 2011) to track the water vapor evaporated north of $70^{\circ} \mathrm{N}$ (Masson-Delmotte et al., 2011). We use the LMDZiso since it has previously been used to understand the isotope variability of the NEEM ice core and was shown to correctly capture interannual variability $\left(R^{2}=0.32\right)$ (SteenLarsen et al., 2011). However the model does also show the same caveats as other GCMs (general circulation models) applied to the Greenland Ice Sheet, having a warm bias and too enriched isotope levels. The super saturation is given by $S=1.00-0.004 \mathrm{~T}$ (Jouzel and Merlivat, 1984). The fractionation coefficient between $0{ }^{\circ} \mathrm{C}$ and $-10^{\circ} \mathrm{C}$ is the linear combination of the fractionation coefficient for liquid and for ice. Below $-10^{\circ} \mathrm{C}$ only the fractionation coefficient for ice is used.

\subsection{Laser instruments and field setup}

We used two different Picarro CRDS (cavity ring downspectroscopy)-analyzers (hereafter Picarro analyzer) and one LGR inc. ICOS (integrated cavity output spectroscopy)analyzer (hereafter LGR analyzer). See Table 1 for overview of the different deployment period and calibration periods. Both types of analyzers are based on cavity-enhanced, nearinfrared laser absorption spectroscopy (CEAS) techniques: the Picarro analyzer specifically uses cavity-ring down spectroscopy (CRDS) whereas the LGR analyzer uses a later CEAS technique called off-axis integrated-cavity-output 


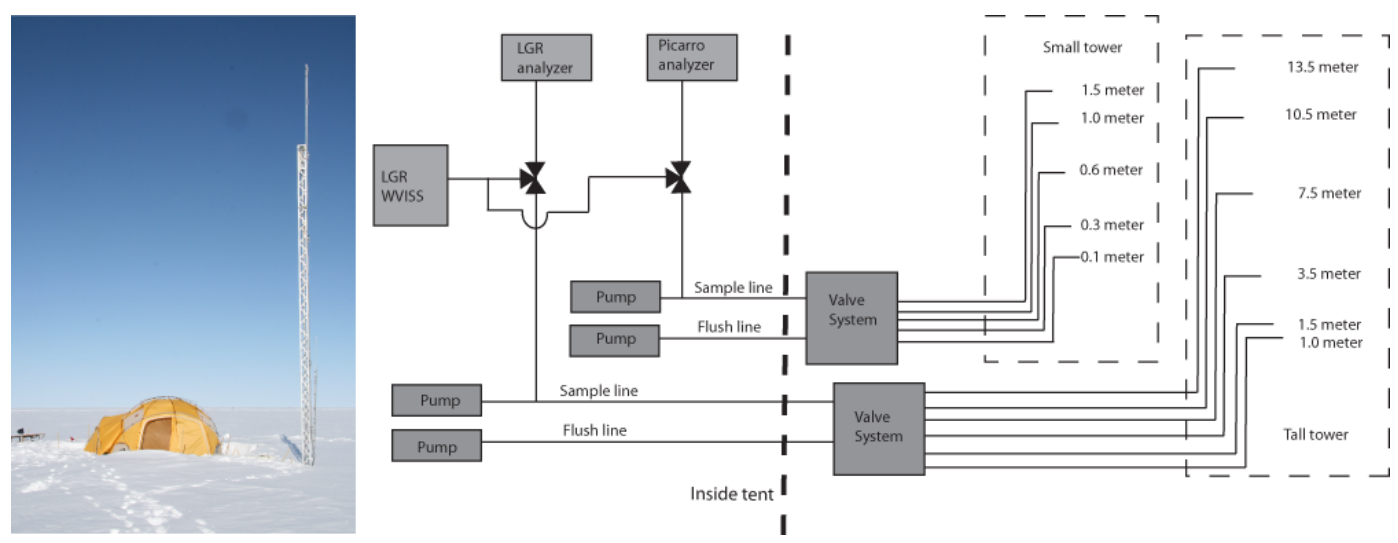

Fig. 1. Illustration of setup with Picarro analyzer connected to small tower and LGR analyzer connected to tall tower.

spectroscopy (OA-ICOS) (Baer et al., 2002). CRDS uses time-based measurements of the exponential decay of light resonating in the optical cavity to quantify the optical loss at different optical wavelengths across a molecular absorption feature (Brand et al., 2009; Crosson et al., 2002). The OAICOS is based on measurement of the transmitted intensity through the cavity, and typically averages several hundred continuous sweeps per second through a molecular absorption feature. After each sweep a ring-down measurement is made to verify the baseline absorption. Both techniques use the Beer-Lambert law to calculate the concentrations of each species, with key differences being that CRDS lends itself to smaller cavity volumes due to its on-axis beam geometry while ICOS offers much faster scan speeds and wider dynamical ranges.

We used the LGR water vapor isotope standard source (WVISS) in a dual-inlet mode to calibrate and drift-correct both the Picarro and LGR analyzer outputs. The WVISS consists of a hot chamber ( $2 \mathrm{~L}$ ) where water of a known isotopic composition is injected using a nebulizer. The water concentration level can be controlled by changing the airflow $\left(2-10 \mathrm{~L} \mathrm{~min}^{-1}\right)$ through the hot chamber. The nebulizer and hot chamber ensure perfect evaporation of the liquid water hence providing an airstream with a known isotopic concentration of the water vapor.

Figure 1 displays our system setup. Two laser analyzers were placed in a heated tent, $\sim 50 \mathrm{~m} \mathrm{SW}$ of the NEEM camp on the edge of the clean air zone (Steen-Larsen et al., 2011). The temperature inside the tent was observed to have fluctuations of up to $20^{\circ} \mathrm{C}$ during a day, in relationship with local weather. To minimize temperature-driven drifts of the analyzers, the Picarro analyzer was placed in a passive temperature regulated box. However, we found that this passive temperature regulation was not sufficient and temperature variations were likely the cause of instrumental instabilities and loss of accuracy (see next sections). The LGR analyzer was placed in an active temperature-regulated box controlling the temperature within $0.2^{\circ} \mathrm{C}$.
Two towers were erected next to each other, with respective heights of $1.5 \mathrm{~m}$ (hereafter small tower) and $13.5 \mathrm{~m}$ (hereafter tall tower). For the majority of the measuring campaign, the Picarro analyzer measured air samples collected on the small tower, while the LGR analyzer measured air samples on the tall tower. On the small tower air was sampled at $0.1,0.3,0.6,1.0$, and $1.5 \mathrm{~m}$ above the snow surface, while on the tall tower air was sampled at 1.0, 1.5, 3.5, 7.5, 10.5 , and $13.5 \mathrm{~m}$. An automatic valve system shifted between the different heights on the two towers and with regular intervals to the calibration unit in order to correct for drifts. Three-way solenoid valves installed on the sample line of each laser analyzer allowed selecting the inflow of either inlet line air or calibration unit air into each of the laser analyzers (see Fig. 1 for an illustration of the setup). The calibration vapor was introduced into the sample line right before the analyzers in order to minimize time spent on calibration due to memory effect of the system. Also to minimize the complexity of this field-deployed system it was decided not to introduce the calibration vapor at the beginning of the inlets on the tower. It was thereby assumed that besides from memory effects no interactions between the ambient vapor and the inside of the sample tubes occurred. This assumption is supported by no observed discrepancy between the measurements from significantly different length of tubes going to respectively the top and bottom inlet on the tower. Each level was sampled for $15 \mathrm{~min}$ of which the first $5 \mathrm{~min}$ were disregarded to remove memory effects. Vapor from the calibration unit was measured for $10 \mathrm{~min}$. To decrease the residence time of air in the inlet lines, the sample line air was pumped at approximately $4 \mathrm{~L} \mathrm{~min}^{-1}$ on the small tower and $6 \mathrm{~L} \mathrm{~min}^{-1}$ on the tall tower. A second pump flushed the other lines not being sampled with about $1 \mathrm{~L} \mathrm{~min}^{-1}$ flow for each of the different lines. The inlet lines consisted of $1 / 4^{\prime \prime}$ outer diameter Synflex 1300 and were heated to a maximum temperature of $60^{\circ} \mathrm{C}$ using a self-regulating heat trace. At the entrance of inlet lines, we used plastic bottles with perforations in the bottom to prevent sucking snow crystals into our 
Table 1. Summary of the different commercial analyzers deployed and the timing of deployment and calibrations.

\begin{tabular}{|c|c|c|c|c|c|}
\hline Instrument & $\begin{array}{l}\text { Serial } \\
\text { number }\end{array}$ & $\begin{array}{l}\text { Deployment period } \\
\text { in } 2010\end{array}$ & $\begin{array}{l}\text { Days of humidity-isotope } \\
\text { response calibration }\end{array}$ & $\begin{array}{l}\text { Days of VSMOW } \\
\text { calibration }\end{array}$ & $\begin{array}{l}\text { Frequency of drift } \\
\text { correction }\end{array}$ \\
\hline Picarro inc. L1102-i & HBDS-48 & Day $\sim 144-154$ & Day 140 & Day 144 & $\begin{array}{l}\sim 1.5 \mathrm{~h} \text { for days } \\
144-147 \text { and } \\
\sim 12 \mathrm{~h} \text { for } \\
\text { days } 148-154\end{array}$ \\
\hline Picarro inc. L1102-i & HBDS-12 & Day $\sim 160-210$ & Day 159 & $\begin{array}{l}\text { Days } 160,171, \\
\text { and } 178\end{array}$ & $\begin{array}{l}\sim 12 \mathrm{~h} \text { for full } \\
\text { period of deployment }\end{array}$ \\
\hline LGR inc. 908-0004-0003 & $10-0037$ & Day $\sim 144-204$ & Days 140 and 159 & $\begin{array}{l}\text { Days } 144,160, \\
171 \text {, and } 178\end{array}$ & $\begin{array}{l}\sim 1.5 \mathrm{~h} \text { for full } \\
\text { period of deployment }\end{array}$ \\
\hline
\end{tabular}

system. Direct observations showed that the temperature inside the clear plastic bottles was about $10^{\circ} \mathrm{C}$ warmer than the ambient air due to solar heating, thereby preventing condensation. All lines were insulated with either Rockwool ${ }^{\mathrm{TM}}$ or polyethylene pipe insulation with a minimum wall thickness of $\sim 2.5 \mathrm{~cm}$.

\subsection{Calibration protocols}

In order to allow the comparison of laser water-vapor measurements with other data (for example with snow samples measured by IRMS or with outputs from isotopic models), it is crucial to produce isotopic-composition data against a known isotopic standard. A thorough characterization of the instrumental system is necessary to detect the variability caused by the analyzer (e.g., due to temperature or humidity responses) from the true atmospheric isotopic signals. The characterization of each individual isotopic analyzer follows in many ways the protocols classically established for IRMS instruments.

We refer the reader to the supplementary material for details but to sum up our calibration protocol, 6 steps must be followed:

1. The humidity-isotope response function must be determined for each instrument. If the field campaign is conducted over an extended period of time, the humidityisotope response function needs to be determined repeatedly due to, e.g., temperature and pressure caused drifts.

2. Using known-isotopic vapor standards, a linear function for transferring the instrument isotopic values to the $\mathrm{V}$ SMOW - SLAP scale must be determined.

To check for stability, this function should be redetermined during extended field campaigns.

3. Raw measurements must be transferred to a reference humidity level using the humidity-isotope response function determined for each instrument.
4. The humidity-corrected measurements must be transferred from the instrument isotope scale to a V-SMOW - SLAP scale.

5. The final calibrated isotopic water vapor data are obtained by drift correcting the V-SMOW - SLAP calibrated measurements using a known vapor standard measured at regular intervals (depending on the drift of the instrument).

6. Possible poor performance can be flagged if measurements of the known vapor standard used for drift corrections are significantly different from the trend of the drift.

\section{Results and discussions}

\subsection{Instrument comparison and overall performance}

Instrument-specific humidity and drift corrections have been applied for each analyzer. A comparison of the corrected results obtained with the two different instruments can therefore provide a stringent assessment of the validity of our calibration protocols.

Figure 2 shows the $\delta \mathrm{D}, \delta^{18} \mathrm{O}$, and d-excess measured at $1 \mathrm{~m}$ above the snow surface by the LGR analyzer and the Picarro analyzer (HBDS 48 for days $~ 144-154$ and HBDS 12 for days $\sim 160-210$ ). From day $\sim 144$ to $\sim 147$, both the LGR and Picarro analyzer (HBDS 48) were installed to measure the same sampled air on the tall tower. During this period, both instruments were drift corrected every $\sim 1.5 \mathrm{~h}$ as explained above and in the supplementary material.

From day $\sim 148$ and through the rest of the campaign, the LGR and Picarro analyzers (HBDS 48 for days 148-154 and HBDS 12 for days 160-210) were measuring air sampled on separate lines. During this time period, the LGR analyzer is drift corrected every $\sim 1.5 \mathrm{~h}$ as in the beginning, while the $\mathrm{Pi}$ carro analyzer is drift corrected every $\sim 12 \mathrm{~h}$. We use the period from day $\sim 144-147$ to compare the performance of the LGR analyzer and Picarro (HBDS 48) analyzer when both 


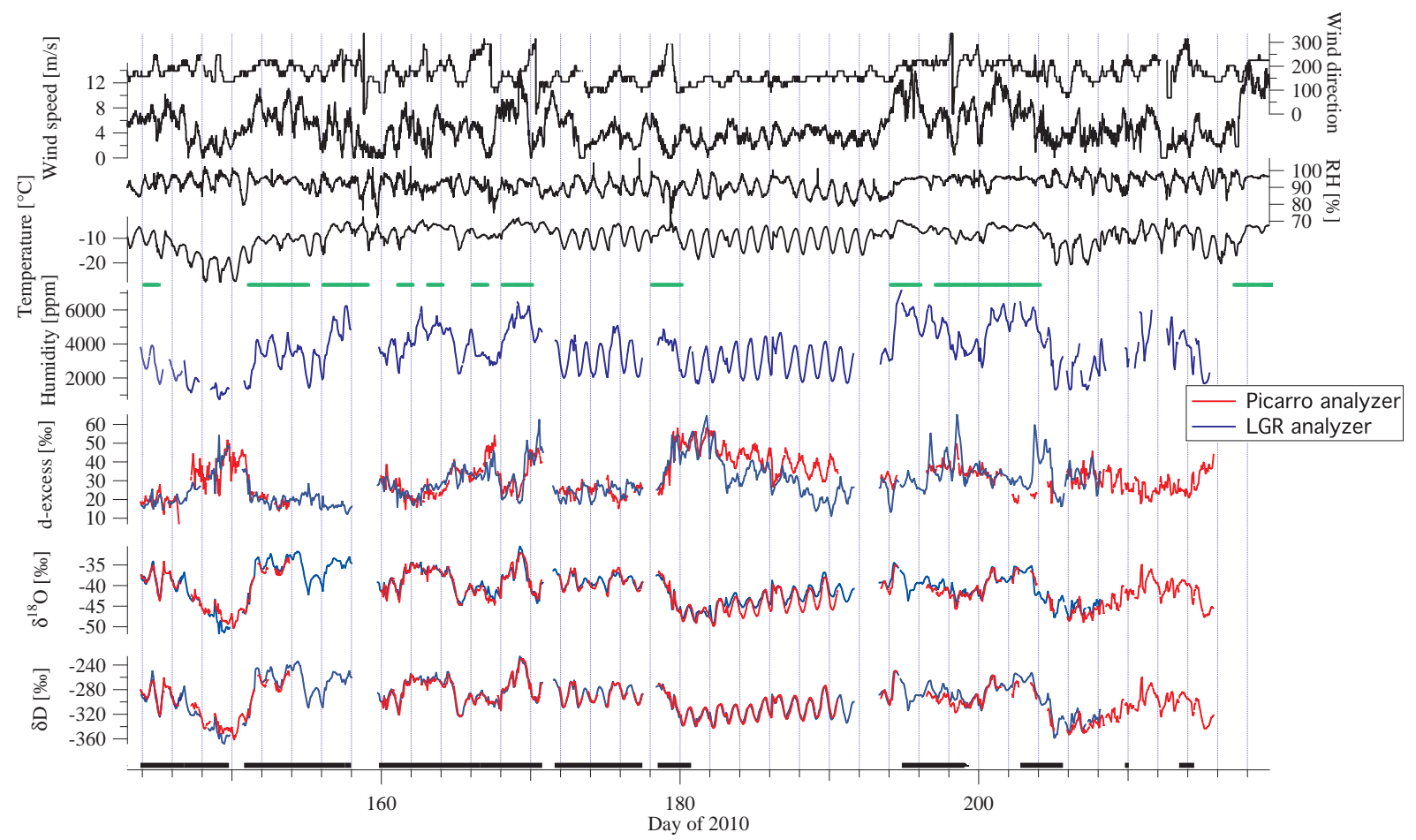

Fig. 2. Meteorological measurements shown in the top four panels. From the top - wind direction in true north, wind speed in $\mathrm{m} \mathrm{s}^{-1}$, relative humidity in $\%$, and temperature in ${ }^{\circ} \mathrm{C}$. Green bars indicate dates with snow showers. Fifth panel shows the humidity in ppmv as measured by the LGR analyzer. The three lower panels show, from below, $\delta \mathrm{D}, \delta^{18} \mathrm{O}$, and d-excess in \%o calibrated on the V-SMOW - SLAP scale. Red line shows data from the Picarro analyzers (HBDS 48 for days $\sim 144-154$ and HBDS 12 for days $\sim 160-210$ ) and blue line shows data from the LGR analyzer. Black bars in the bottom of the figure indicate the period where calibration was working optimally.

instruments are drift corrected every $\sim 1.5 \mathrm{~h}$. To compare the performance of the Picarro (HBDS 12) analyzer when drift corrected every $\sim 12 \mathrm{~h}$, we use the period from $\sim 160-180$. This period was selected because both instruments and calibration unit were optimally working.

For the first inter-calibration period, the inter-instrument difference in the $\delta \mathrm{D}$ data is $0.2 \pm 1.4 \%$ (standard deviation calculated from 191 points, averaged over $10 \mathrm{~min}$ ). Similarly, the difference in $\delta^{18} \mathrm{O}$ has a mean value of $0.02 \pm 0.23 \%$ o $(N=191)$. Due to the small mean of the differences in $\delta \mathrm{D}$ and $\delta^{18} \mathrm{O}$, we conclude that we have an optimal humidityisotope response calibration and V-SMOW calibration for both machines. Based on the standard deviation of the differences we conclude that with $\sim 1.5 \mathrm{~h}$ calibration we have a precision on the LGR and Picarro analyzer (HBDS 48) of $\pm 1.4 \%$ ofor $\delta \mathrm{D}$ and $\pm 0.23 \%$ or $\delta^{18} \mathrm{O}$.

During the second period, where the LGR and Picarro analyzer (HBDS 12) were measuring on separate lines, we compare the measurements carried out at $1.0 \mathrm{~m}$ by the LGR analyzer with the closest timewise measurement carried out by the Picarro analyzer at any of the heights $0.3,0.6,1.0$, or $1.5 \mathrm{~m}$. The measurements are drift corrected and transferred to the V-SMOW - SLAP scale. The difference between the LGR and Picarro analyzers is $0.7 \pm 5.4 \%$ for $\delta \mathrm{D}(N=231)$ and $0.14 \pm 0.9 \%$ for $\delta^{18} \mathrm{O}(N=231)$. We have no reason to believe that the accuracy of the LGR analyzer and correction protocol have changed. The difference between the LGR and Picarro analyzers is a composite of the precision of the LGR and of the Picarro analyzer, plus the uncertainty introduced by the increased time between calibrations, and the noise caused by the different sampling lines (up to $0.7 \mathrm{~m}$ height difference). Using the standard deviation of the distribution of differences we conservatively estimate the precision of the Picarro analyzer (HBDS 12) with $12 \mathrm{~h}$ drift correction to be $\pm 5.4 \%$ for $\delta \mathrm{D}$ and $0.9 \%$ for $\delta^{18} \mathrm{O}$. Table 2 summarizes these findings on the precision and accuracy of our measurements. Using this, the uncertainty on the d-excess of the LGR and Picarro (HBDS 48) analyzers, when averaged over a 10 min time window, will be $2.3 \%$ when using $1.5 \mathrm{~h}$ drift correction, while when using $12 \mathrm{~h}$ drift correction on the Picarro (HBDS 12) analyzer the uncertainty of the d-excess becomes $\sim 9 \%$. We attribute this large increase in uncertainty to the large temperature variations, which the Picarro analyzers were subjected to, while the LGR analyzer was placed in a temperature-controlled box. It should also be noted that the Picarro analyzers are operated outside the humidity range specified by the manufacturer. 
Table 2. Direct comparison between LGR analyzer and Picarro analyzers (HBDS 12 and HBDS 48). The measurements are averaged over a period of $10 \mathrm{~min}$.

\begin{tabular}{|c|c|c|c|c|c|}
\hline \multirow[t]{2}{*}{ Differerence } & \multicolumn{2}{|c|}{$\delta \mathrm{D}$} & \multicolumn{2}{|c|}{$\delta^{18} \mathrm{O}$} & \multirow{2}{*}{ 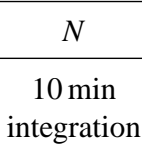 } \\
\hline & Mean & $\begin{array}{l}\text { Standard } \\
\text { deviation }\end{array}$ & Mean & $\begin{array}{l}\text { Standard } \\
\text { deviation }\end{array}$ & \\
\hline $\begin{array}{l}\text { LGR }- \text { Picarro (HBDS } 48 \text { ) analyzer. } \\
1.5 \mathrm{~h} \text { drift correction for both. } \\
\text { Days } \sim 144 \text { to } \sim 147 \\
\text { Measurement on same inlets }\end{array}$ & $0.2 \% 0$ & $1.4 \% o$ & $0.02 \% o$ & $0.23 \%$ & 191 \\
\hline $\begin{array}{l}\text { LGR - Picarro (HBDS } 12 \text { ) analyzer. } \\
1.5 \mathrm{~h} \text { drift correction for LGR analyzer. } \\
12 \mathrm{~h} \text { drift correction for Picarro anlayzer. } \\
\text { Days } \sim 160 \text { to } \sim 180 \\
\text { Measurement on different inlets }\end{array}$ & $0.7 \%$ & $5.4 \%$ & $0.14 \%$ & $0.90 \%$ & 231 \\
\hline
\end{tabular}

\section{2 $\delta \mathrm{D}$ vs. $\delta^{18} \mathrm{O}$}

Figure 2 shows the water vapor isotopic composition measured at $1 \mathrm{~m}$ above the snow surface. The Picarro analyzers (red solid line) measured this first on the tall tower (days $\sim 144-147$ ) and then on the small tower (days $\sim 148-154$ and $\sim 160-210$ ) while the LGR analyzer measured this on the tall tower (blue solid line). The black bars in the bottom of the figure illustrate the time intervals when the calibration routine was working optimally (Sect. 2.5). Unfortunately, during the second half of the field campaign, the stability of the calibration unit was affected by an undetected loose wire in the WVISS. Based on analysis of the signal, we find that the largest confidence should be placed in the signal from the LGR analyzer, except the last 5 days of the campaign.

We notice in Fig. 2 several events of very high d-excess levels in the water vapor. In order to obtain an objective identification of high d-excess events, we perform a cluster analysis using an expectation-maximization algorithm for Gaussian mixture models (Moon, 1996). This analysis shows a distinct cluster with a mean $(\mu)$ of $\sim 23 \%$ and standard deviation $(\sigma)$ of $\sim 5 \%$, and a second cluster centered around $\mu=\sim 37 \%$ o with $\sigma=\sim 8 \%$. We subjectively define normal $\mathrm{d}$-excess as values being within $\pm 0.5 \sigma$ of the $\mu$ of the main cluster and high d-excess as being larger than the $\mu+3 \sigma$ of the main cluster.

Figure 3 shows the observation by the LGR analyzer for $\delta \mathrm{D}$ vs. $\delta^{18} \mathrm{O}$ at $1 \mathrm{~m}$ above the snow surface. The red dots indicate data obtained during periods of high d-excess as defined above while blue dots indicate data obtained during periods of normal d-excess. Black dots are data that do not fall into any of the two categories. Red crosses represent mean daily outputs from the LMDZiso model (Risi et al., 2010a, b). These model outputs are also presented in Fig. 6.

We first compare the $\delta \mathrm{D}$ vs. $\delta^{18} \mathrm{O}$ slope of our water vapor monitoring data. A best linear fit through all measurements

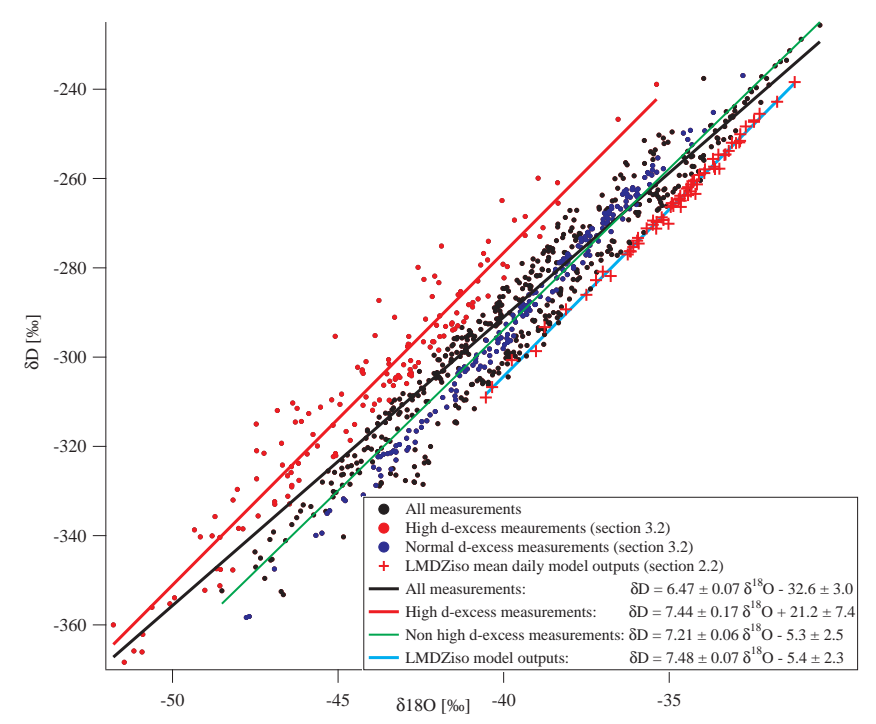

Fig. 3. $\delta \mathrm{D}$ vs. $\delta^{18} \mathrm{O}$ measured by the LGR analyzer $1 \mathrm{~m}$ above the snow surface. Red dots correspond to data during periods of high d-excess. Blue dots correspond to data during periods of normal dexcess. Black dots correspond to data not falling into any category. Red crosses are mean daily model outputs from LMDZiso. Uncertainties on estimated fits represent one standard deviation.

(black solid line) reveals a slope of $6.46 \pm 0.07$ and intercept of $-32.6 \pm 3.0 \%$. The slope is comparable to the best fit through the cold trap vapor measurements presented in Steen-Larsen et al. (2011), where the slope was found to be $6.89 \pm 0.15$ and intercept $-17.8 \pm 6.0 \%$. We consider this as support for an only negligible uncorrected bias in our measurements presented here. For the high d-excess data only, we obtain a significantly different slope and intercept, respectively $7.44 \pm 0.17$ and $21.2 \pm 7.4 \%$ (red solid line). Removing the set of measurements corresponding to high dexcess as defined above, a best fit through the remaining 
measurements (green solid line) reveals a slope and intercept of respectively $7.21 \pm 0.06$ and $-5.3 \pm 2.5$. We conclude that (i) the continuous measurement data are consistent with the earlier cold trap data available for NEEM water vapor; (ii) that the $\delta \mathrm{D}$ vs. $\delta^{18} \mathrm{O}$ slope is systematically lower in the NEEM vapor than in the NEEM precipitation, estimated to be $\sim 7.6$ (Steen-Larsen et al., 2011); (iii) that the high versus normal d-excess events correspond to different $\delta \mathrm{D}$ vs. $\delta^{18} \mathrm{O}$ relationships and therefore different distillation/source histories.

We now compare the outputs of the LMDZiso model with our observations. First, we note that the simulated water vapor $\delta \mathrm{D}$ vs. $\delta^{18} \mathrm{O}$-relationship $(7.48 \pm 0.07)$ shows a slope significantly larger than observations at NEEM. This higher slope is consistent with the fact that LMDZiso produces toolow d-excess levels in both summer and annual mean precipitation at NEEM (Steen-Larsen et al., 2011). Moreover, LMDZiso produces very similar slopes in the vapor (7.48) and in the summer precipitation $(\sim 7.6$, in good agreement with the observed slope of $\sim 7.6$ at NEEM; Steen-Larsen et al., 2011). Assuming that the isotopic vapor measurements are representative for the summer vapor at NEEM, we conclude that the LMDZiso does not correctly resolve the processes accounting for the observed different slopes in water vapor and snowfall. This mismatch may be linked with the physical parameterization of LMDZiso related either to the formation of snow crystals, with the representation of atmosphere-snow surface interactions, boundary layer dynamics, or physical parameterization of the evaporation in the source region. Table 3 summarizes the slope and intersect for observed and modeled water vapor and precipitation at NEEM.

\subsection{Diurnal signal}

The isotopic and meteorological data displayed in Fig. 2 depict a diurnal cycle in both humidity and the isotopic composition with a respective peak-to-peak variability of $\sim 1800$ ppmv and $\sim 36 \%$ o $(\delta \mathrm{D})$. A weak diurnal cycle at the limit of detection might be observed in the d-excess from the LGR analyzer with a peak-to-peak variability of $\sim 6 \%$ o in phase with the isotopic $\left(\delta^{18} \mathrm{O}\right.$ and $\left.\delta \mathrm{D}\right)$ variations. Several periods characterized by abnormally multiday high or low mean isotopic levels have a null or very weak diurnal signal. Some of these intervals are marked by very high d-excess levels, above $\sim 40 \%$.

The period from day 180 to 190 is marked by particularly strong diurnal variability (Figs. 2, 4). This is also seen in the $1 \mathrm{~m}$, diurnal surface-air temperature variability, which shows on average a peak-to-peak variability of $10^{\circ} \mathrm{C}$. In order to further characterize this variability, we analyze the vertical gradients in humidity and water vapor isotopic composition. During this period, the humidity is on average $\sim 350 \mathrm{ppmv}$ higher at $13.5 \mathrm{~m}$ compared to the $1.0 \mathrm{~m}$ height during the evening (00:00 UTC, Universal Time Coordinated; 22:00 LT, local time) when the surface cools down. A reverse effect is seen during the morning (12:00-15:00 UTC, 10:0013:00 LT) when a $\sim 200$ ppmv excess of humidity exists near the surface. During the evening (marked by a humidity deficit at the surface), water vapor $\delta \mathrm{D}$ is $\sim 4.5 \%$ enriched at $13.5 \mathrm{~m}$ height compared to the $1.0 \mathrm{~m}$ level; a reversed difference of $\sim 4.0 \% \circ \delta \mathrm{D}$ is observed during the morning. The diurnal variation of the gradient with height in both humidity and isotopic composition is an indication for the snow surface acting successively as a moisture sink (evening) and source (midday) when stable weather conditions exist. This implies that the surface water vapor could be in isotopic equilibrium with the snow surface during part of the day. Steen-Larsen et al. (2011) compared the isotopic compositions of cryogenically collected vapor samples and the isotopic composition of sampled precipitation and reached the same conclusion. The cold trap measurements however did not have sufficient temporal resolution (maximum 4 daily samples) to allow a characterization of this diurnal cycle. The lack of monitoring of the boundary layer's vertical structure at NEEM prevents us from further investigating the relationships between boundary layer dynamics and surface water vapor isotopic composition. We briefly note that a series of unresolved questions exist: the magnitude of the firn-air fluxes on a diurnal scale; the influence on the diurnal variability of the water vapor isotope by boundary layer dynamics; and the link between surface water vapor and condensation water vapor forming snow crystals in the clouds.

\section{4 d-excess signal}

We qualitatively compare the d-excess record shown in Fig. 2 with the meteorological and isotopic observation in order to understand if local mechanisms or advection are responsible for producing high d-excess events. First, we note that after the first period with high d-excess (day 154-156), d-excess appears to be independent of variations in local surface humidity, temperature, or isotopic composition. We therefore do not find any local, qualitative explanation for the high dexcess events.

Figure 5 shows a comparison of 5-day backward trajectories for high d-excess periods (red) and normal d-excess periods (blue). The back-trajectories corresponding to normal dexcess levels are relatively homogeneous, originating southwards of NEEM (very few from the east or west of NEEM). By contrast, most of the back-trajectories corresponding to high d-excess periods have a westward origin; some of them also have east and south-east origins. The shorter isotopic record presented by Steen-Larsen et al. (2011) also shows a period of high d-excess, which corresponds to air masses originating to the west of Greenland.

The d-excess of the water vapor in an air parcel depends on several things: the condition during the evaporation in the source region, the cumulated amount of condensation from source to sink, the cleanliness of the air, the history 
Table 3. Overview of slope and intersect for $\delta \mathrm{D}$ vs. $\delta^{18} \mathrm{O}$ for observed and modeled water vapor and precipitation.

\begin{tabular}{|c|c|c|c|c|c|c|c|}
\hline & $\begin{array}{c}\text { Cold trap } \\
\text { measurements } \\
\text { (Steen-Larsen et al., 2011) }\end{array}$ & $\begin{array}{l}\text { All vapor } \\
\text { measurements } \\
\text { (this work) }\end{array}$ & $\begin{array}{l}\text { High d-excess } \\
\text { measurements } \\
\text { (this work) }\end{array}$ & $\begin{array}{l}\text { Excluding high d-excess } \\
\text { measurements } \\
\text { (this work) }\end{array}$ & $\begin{array}{c}\text { Precipitation } \\
\text { (Steen-Larsen et al., 2011) }\end{array}$ & $\begin{array}{l}\text { LMDZiso vapor } \\
\text { simulation } \\
\text { this period }\end{array}$ & $\begin{array}{l}\text { LMDZiso } \\
\text { summer } \\
\text { precipitation }\end{array}$ \\
\hline $\begin{array}{l}\delta \mathrm{D} \text { vs. } \\
\delta^{18} \mathrm{O} \text { slope }\end{array}$ & $6.89 \pm 0.15$ & $6.46 \pm 0.07$ & $7.44 \pm 0.17$ & $7.21 \pm 0.06$ & $7.57 \pm 0.14$ & $7.48 \pm 0.07$ & $\sim 7.6$ \\
\hline $\begin{array}{l}\delta \mathrm{D} \text { vs. } \\
\delta^{18} \mathrm{O} \text { intersect }\end{array}$ & $-17.8 \pm 6.0$ & $-32.6 \pm 3.0$ & $21.2 \pm 7.4$ & $-5.3 \pm 2.5$ & $0.2 \pm 2.8$ & $-5.4 \pm 2.3$ & NN \\
\hline
\end{tabular}

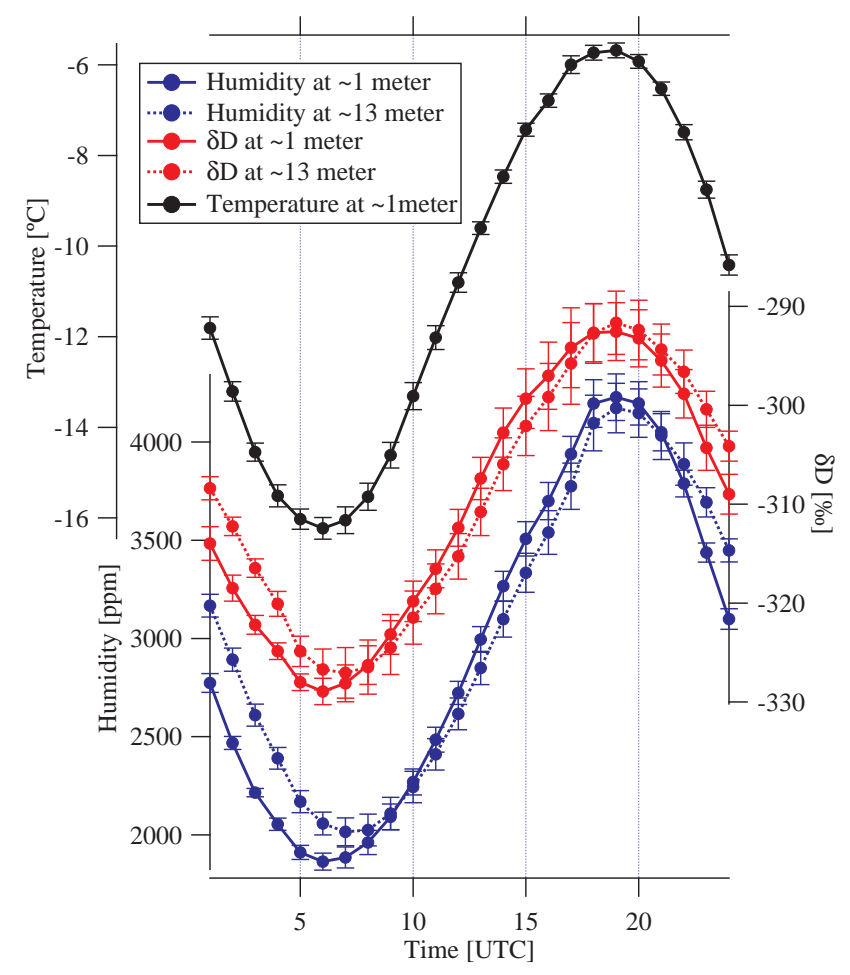

Fig. 4. The mean diurnal cycle on days with clear sky and calm weather. Stacked based on diurnal cycles between days $\sim 180$ and $\sim 190$. Error bars indicate the standard deviation on the mean. Solid lines represent measurements at $\sim 1 \mathrm{~m}$ above snow surface. Dashed lines represent measurements at $\sim 13 \mathrm{~m}$ above snow surface. Blue lines represent humidity, red lines represent $\delta \mathrm{D}$, and black line represents temperature.

of the super saturation in the cloud, and the temperature at which snow crystals starts to form. The last process is only expected to affect d-excess at very low condensation temperatures $\left(<-25^{\circ}\right.$; Jouzel and Merlivat, 1984; Hoffmann et al., 1998). During the periods of high d-excess observed at NEEM, no exceptional cold-surface-temperatures were observed (Fig. 2); we assume that cloud temperatures and surface temperatures are related. Furthermore, back trajectories do not show high-elevation transportation paths for the air masses corresponding to high d-excess days. Since the back trajectories are only 5 days back we do not have any information about origin before this period. The absence of any systematic anticorrelation between d-excess and $\delta \mathrm{D}$ rules out a dominant effect of condensation. This leads to the hypothesis that high d-excess events are associated with moisture origin, possibly preserved from evaporation conditions.

The process of creating high d-excess in the atmospheric water vapor through strong evaporation from the sea surface was observed previously by Gat et al. (2003) for the eastern Mediterranean and by Kurita (2011) for the Bering Strait. The high d-excess in the air masses originating west of Greenland can be explained similarly. Figure 5 illustrates the Arctic sea-ice extent during May and August of 2010. The westerly-trajectories associated with high d-excess (Fig. 5) have all crossed the Baffin Bay area, southwards of the seaice cover, and open water between the Arctic sea ice and the North American continent. As the humidity-depleted cold polar air masses cross the sea-ice margin, strong evaporation from the open-water bodies will result in kinetic effects leading to high d-excess in the water vapor. This hypothesis is supported by the observation of high d-excess values in the surface water vapor near the sea-ice margin (Kurita, 2011).

No such simple explanation can be provided for high dexcess episodes when air masses are originating from the east or southeast of NEEM. These trajectories are however marked by shorter transportation distances (Fig. 5). We suggest that a large fraction of the moisture transported by these trajectories is provided by evaporation at the Arctic sea-ice margin areas east of Greenland.

To support our hypothesis that high d-excess values are associated with Arctic origin, where strong kinetic fractionation occurs at evaporation, we use LMDZiso water tagging diagnostics (Risi et al., 2010b) shown in Fig. 6. This diagnosis complements the investigation of air mass origins using back-trajectories by tracking water vapor transportation and accounting for the effect of air mass mixing.

GCMs have some uncertainties in their representation of sub-grid physical processes, but they are more robust in their simulation of large-scale dynamics. The consistency of the LMDZiso simulation with large-scale dynamics is warranted by the wind nudging towards the ECMWF operational analysis, which were shown to accurately capture Arctic circulation (e.g., Jakobson et al., 2012). As a result, LMDZiso correctly captures the observed patterns and magnitudes of NEEM mean daily surface-humidity variability (the correlation coefficient and ratio of standard deviation are respectively 0.70 and 0.56 ) as shown in Fig. 6. 


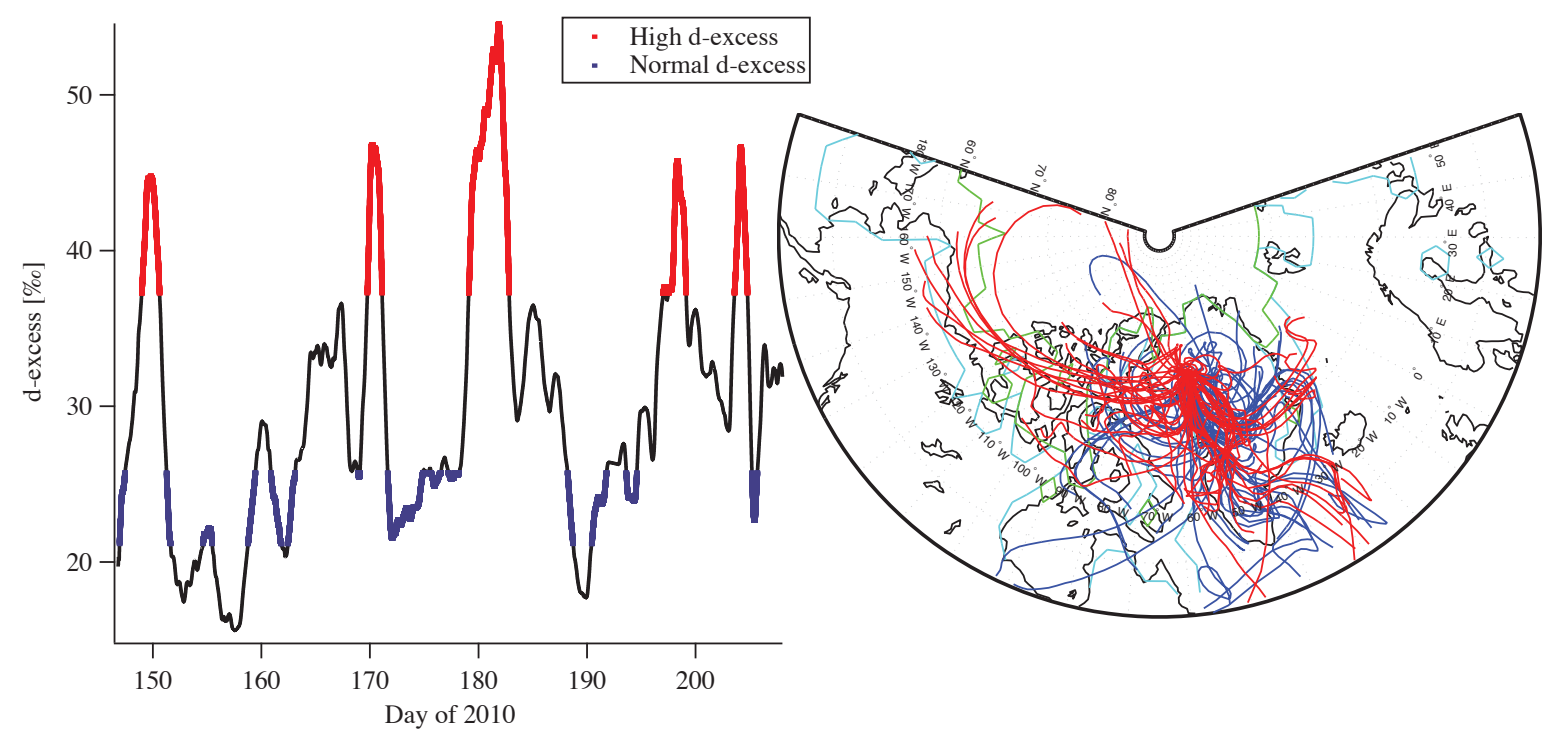

Fig. 5. The left panel shows the observed d-excess from the LGR analyzer smooth using a $24 \mathrm{~h}$ moving window. Red indicates periods with high d-excess defined as d-excess being larger than 3 standard deviations from the mean value of the main cluster. Blue indicates periods of normal d-excess defined a being within \pm 0.5 standard deviation of the mean value of the main cluster. The right panel shows back trajectories calculated using the FLEXTRA model 5 days back (Stohl et al., 1995, 1998). Red back trajectories correspond to periods of high d-excess while blue trajectories correspond to periods of normal d-excess. Cyan solid line indicates sea-ice extent (concentration $>15 \%$ ) for May while green solid line indicates sea-ice extent for August based on data from Nimbus-7 SSMR and DMSP SSM/I passive microwave data (Fetterer et al., 2002).

The proportion of the moisture originating from the Arctic as diagnosed from water tagging appears to co-vary with the observed NEEM d-excess (correlation coefficient of 0.30). Days with high d-excess around days 170, 198 and 203 correspond to maxima in the fraction of NEEM moisture coming from the Arctic. This confirms our result from backtrajectory analysis, and supports our hypothesis of the link between high d-excess and Arctic origin.

The model-data comparison further informs on the causes of the observed $\delta \mathrm{D}$ and d-excess variability. $\delta \mathrm{D}$ variations are reasonably well captured by LMDZiso (correlation coefficient of 0.67 and ratio of standard deviation of 0.51 ), and so are d-excess variations before mid-June (correlation coefficient of 0.46 and ratio of standard deviation of 0.27 ). This suggests that $\delta \mathrm{D}$ and d-excess variability before midJune are mainly controlled by large-scale dynamics. In contrast, LMDZiso is unable to simulate any significant d-excess variations during mid-summer, while large variations are observed (Fig. 6). The variance for this period of the observed d-excess is $\sim 67 \% o^{2}$ while the variance for the modeled dexcess is $\sim 1 \% o^{2}$. We suspect that this model caveat could be linked to subgrid model physics, especially the difficulty to correctly simulate relative humidity at the surface of the Arctic Ocean. This was indeed demonstrated by the poor performance of LMDZiso against relative-humidity data from the SHEBA (Surface Heat Budget of the Arctic Ocean) campaign in the Arctic ocean (Persson et al., 2002). We cannot exclude that the lack in simulating the high d-excess vari- ability is caused by a wrong parameterization of the processes coupled to the transport of moisture or snow crystal formation in the modeled hydrological cycle. It is outside the scope of this paper to study these processes in more details. However we plan to undertake a detailed study using several isotope-enabled GCMs and water vapor isotope measurements from subsequent seasons to investigate especially the parameterization of moisture transport from subtropics to Arctic regions.

On annual timescales Steen-Larsen et al. (2011) reported, for a shallow ice core drilled at the NEEM site, a positive correlation $\left(R^{2}=0.2\right)$ between winter Arctic Oscillationanomaly and annual d-excess. Positive AO and NAO (North Atlantic Oscillation) configurations, associated with respectively stronger high-latitude westerlies (Thompson and Wallace, 1998) and dominant East Greenland moisture sources (Sodemann et al., 2008), may favor the transport of high dexcess moisture to NEEM. It remains a speculation in this paper, but maybe part of the d-excess signal observed in ice cores drilled at NEEM need to be attributed to inter-annual variations in relative moisture arriving at NEEM originating from Arctic moisture sources.

\section{Conclusions and perspectives}

We have demonstrated the ability of laser analyzers to produce reliable measurements of Greenland surface water isotopic composition. We have proposed calibration protocols 


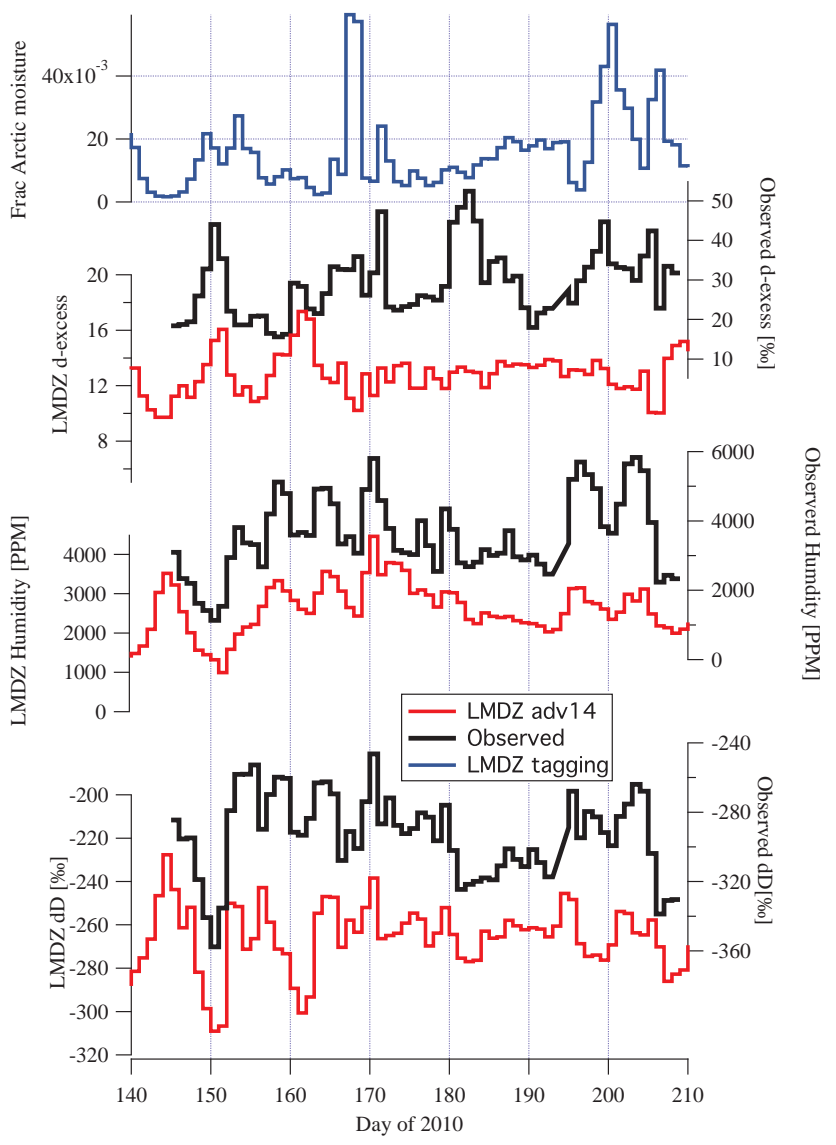

Fig. 6. Comparison between daily mean GCM model outputs from LMDZiso with water tagging and observed daily mean humidity and isotopic composition from $1 \mathrm{~m}$ above the snow surface by the LGR analyzer.

to account for humidity and drift effects, and to deliver measurements against V-SMOW references. The systematic comparison of different CRDS analyzers allows us to demonstrate the reliability of our corrections and to estimate the overall analytical precision. When run with frequent drift corrections ( $1.5 \mathrm{~h}$ frequency), we obtain interinstrument standard deviations of $1.4 \%$ and $0.23 \%$ for $\delta \mathrm{D}$ and $\delta^{18} \mathrm{O}$, respectively. When drift correcting the Picarro analyzer only every $\sim 12 \mathrm{~h}$, the dispersion increases by a factor of $3-4$ to $5.4 \%$ and $0.9 \%$ for $\delta \mathrm{D}$ and $\delta^{18} \mathrm{O}$, respectively. We speculate that this significant increase in uncertainty is caused by large temperature variations in the tent and thus around the Picarro analyzer, which did not benefit from the same setup as the LGR analyzer (temperature regulation, frequency of calibrations).

We have shown that water vapor isotope measurements are indeed feasible at low humidity concentrations but corrections are needed to remove biases. Especially for field deployments of laser analyzers either frequent drift correction is needed or significant temperature stability of the analyzer must be applied. Having two independent analyzers allow for detection of issues with the calibration.

Our data reveal a diurnal variability in surface humidity and water vapor isotopic composition (at the limit of detection for d-excess) under stable weather conditions. This diurnal variability is characterized by strongly correlated humidity and isotopic composition gradients from 0.1 to $13.5 \mathrm{~m}$ height. We interpret this as indications of firn-air moisture fluxes, which likely depend on the upper firn heat budget and on the atmospheric boundary layer dynamics. Further investigations of this diurnal cycle are expected to shed light on post-depositional processes affecting the isotopic composition of the snow, with large implications for an improved understanding of the isotopic diffusion in the ice core records. The isotopic data should in the future be combined with local atmospheric and surface mass-balance modeling, and may be helpful to assess the magnitude of the sublimation and condensation fluxes.

Our data also depict another mode of isotopic variability; this mode is marked by changes in the daily mean values of the humidity and isotopic composition at the synoptic scale. These synoptic events are characterized by a lack of diurnal cycle in temperature and isotopic composition, and for the majority of the events by slightly higher daily mean temperatures. An indication of larger-than-averaged wind speeds coming from the west can also be observed in a majority of the cases. The lack of diurnal cycles in the isotopic composition is probably related to cloudy conditions, inhibiting diurnal variations in surface temperature. Further investigations are needed to understand the cause of these fluctuations, i.e, snow surface-air exchanges upstream, or changes in air mass origins, or exchanges with snowfall.

Particularly remarkable are periods of vapor with very high d-excess. Back trajectories relate these high d-excess events with air originating from the west and east of Greenland. Water tagging in one single atmospheric model confirms the relationship between high d-excess events and Arctic moisture sources as well. Future work will address this using a suite of models with different physical parameterization as well as by combining precipitation and vapor measurements. In line with earlier studies, we attribute the high d-excess events to large kinetic effects occurring at the seaice margin as dry air from over the sea ice is advected over the open water. It appears that the LMDZiso model may not correctly resolve these subgrid processes, and cannot capture the observed high d-excess events at NEEM.

The relationships between the fraction of Arctic moisture sources and NEEM d-excess needs to be further investigated. Our study is restricted to a few summer events. Similar processes may relate moisture sources formed at the sea-ice margin and high d-excess during winter. We speculate that the observed northward spatial d-excess gradient (Steen-Larsen et al., 2011; Masson-Delmotte et al., 2005) could partly be explained by a northward increase in the fraction of Greenland precipitation provided by Arctic moisture 
sources. Furthermore, our results have implications for past temperature estimates from ice core data. We indeed suggest that past d-excess variations preserved in ice cores drilled at NEEM may inform on variations in Arctic moisture transported to NEEM.

Our new dataset demonstrates the value of continuous water vapor isotopic measurements for enhancing our understanding of the hydrological cycle of the Arctic, and assessing the ability of atmospheric general-circulation models to capture moisture origins. In a warmer Arctic, with a reduced sea-ice cover, changes in moisture sources indeed appear to be strongly model-dependent (Masson-Delmotte et al., 2011; Sime et al., 2013). Only detailed process studies, enabled by continuous monitoring, can help to reduce these uncertainties. Such monitoring efforts should be extended over longer timescales, in order to address seasonal variations as well as interannual variations and their relationship with weather patterns, on timescales relevant for an improved interpretation of ice core records.

\section{Supplementary material related to this article is available online at: http://www.atmos-chem-phys.net/13/ 4815/2013/acp-13-4815-2013-supplement.pdf.}

Acknowledgements. NEEM is directed and organized by the Center of Ice and Climate at the Niels Bohr Institute and US NSF, Office of Polar Programs. It is supported by funding agencies and institutions in Belgium (FNRS-CFB and FWO), Canada (GSC), China (CAS), Denmark (FIST), France (IPEV, INSU/CNRS and ANR VMC NEEM), Germany (AWI), Iceland (RannIs), Japan (NIPR), Korea (KOPRI), The Netherlands (NWO/ALW), Sweden (VR), Switzerland (SNF), United Kingdom (NERC) and the USA (US NSF, Office of Polar Programs). The numerical simulations with LMDZiso were performed on the NEC-SX8 of the IDRIS/CNRS computing center. The work was supported by the Danish Council for Independent Research - Natural Sciences grant number 09-072689 and 10-092850, by the French Agence Nationale de la Recherche (grant VMC NEEM and CEPS GREENLAND). Aaron van Pelt (Picarro Inc.) and Feng Dong (Los Gatos Research Inc.) supported this work with invaluable assistance. Nimbus-7 SMMR and DMSP SSM/I-SSMIS passive microwave data was obtained from NSIDC. The authors thank David Fisher and an anonymous reviewer for valuable suggestions during the review process, which improved the final version of this manuscript.

Edited by: T. Röckmann

\section{References}

Angert, A., Lee, J. E., and Yakir, D.: Seasonal variations in the isotopic composition of near-surface water vapour in the eastern mediterranean, Tellus B, 60, 674-684, doi:10.1111/j.16000889.2008.00357.x, 2008.
Baer, D. S., Paul, J. B., Gupta, M., and O'Keefe, A.: Sensitive absorption measurements in the near-infrared region using off-axis integrated-cavity-output spectroscopy, Appl. Phys. B-Lasers O., 75, 261-265, doi:10.1007/s00340-002-0971-z, 2002.

Brand, W. A., Geilmann, H., Crosson, E. R., and Rella, C. W.: Cavity ring-down spectroscopy versus high-temperature conversion isotope ratio mass spectrometry; a case study on $\delta 2 \mathrm{~h}$ and $\delta 180$ of pure water samples and alcohol/water mixtures, Rapid Commun. Mass Sp., 23, 1879-1884, doi:10.1002/rcm.4083, 2009.

Ciais, P. and Jouzel, J.: Deuterium and oxygen 18 in precipitation: An isotopic model including mixed cloud processes, J. Geophys. Res., 99, 16793-16804, 1994.

Craig, H. and Gordon, L. I.: Deuterium and oxygen 18 variations in the ocean and the marine atmosphere, in: Stable isotopes in oceanographic studies and paleotemperatures, 26-30 July 1965, Spoleto, Italy, 1965.

Crosson, E. R., Ricci, K. N., Richman, B. A., Chilese, F. C., Owano, T. G., Provencal, R. A., Todd, M. W., Glasser, J., Kachanov, A. A., Paldus, B. A., Spence, T. G., and Zare, R. N.: Stable isotope ratios using cavity ring-down spectroscopy: Determination of c13/c-12 for carbon dioxide in human breath, Anal. Chem., 74, 2003-2007, doi:10.1021/ac025511d, 2002.

Dansgaard, W.: Oxygen-18 abundance in fresh water, Nature, 174, 234-235, 1954.

Dansgaard, W.: Stable isotopes in precipitation, Tellus, 16, 436468, 1964.

Fetterer, F., Knowles, K., Meier, W., and Savoie, M.: Sea ice index. Boulder, colorado USA: National snow and ice data center, Digital media, updated 2009, 2002.

Fisher, D. A.: A zonally-averaged stable-isotope model coupled to a regional variable-elevation stable-isotope model, Ann. Glaciol., 14, 65-71, 1990.

Fisher, D. A.: Remarks on the deuterium excess in precipitation in cold regions, Tellus B, 43, 401-407, 1991.

Fisher, D. A.: Stable isotope simulations using a regional stable isotope model coupled to a zonally averaged global model, Cold Reg. Sci. Technol., 21, 61-77, 1992.

Frankenberg, C., Yoshimura, K., Warneke, T., Aben, I., Butz, A., Deutscher, N., Griffith, D., Hase, F., Notholt, J., Schneider, M., Schrijver, H., and Rockmann, T.: Dynamic processes governing lower-tropospheric hdo/h(2)o ratios as observed from space and ground, Science, 325, 1374-1377, doi:10.1126/science.1173791, 2009.

Gat, J. R., Klein, B., Kushnir, Y., Roether, W., Wernli, H., Yam, R., and Shemesh, A.: Isotope composition of air moisture over the mediterranean sea: An index of the air-sea interaction pattern, Tellus B, 55, 953-965, 2003.

Grootes, P. M. and Stuiver, M.: Oxygen 18/16 variability in greenland snow and ice with $10^{-3}$ - to $10^{5}$-year time resolution, J. Geophys. Res., 102, 26455-26470, 1997.

Hoffmann, G., Stievenard, M., Jouzel, J., White, J. W. C., and Johnsen, S. J.: Deuterium excess record from central greenland, IAEA-SM-349/54, 591-602, 1998.

Hoffmann, G., Jouzel, J., and Masson, V.: Stable water isotopes in atmospheric general circulation models, Hydrol. Process., 14, 1385-1406, 2000.

Hourdin, F., Musat, I., Bony, S., Braconnot, P., Codron, F., Dufresne, J. L., Fairhead, L., Filiberti, M. A., Friedlingstein, P., Grandpeix, J. Y., Krinner, G., Levan, P., Li, Z. X., and Lott, F.: 
The $1 m d z 4$ general circulation model: Climate performance and sensitivity to parametrized physics with emphasis on tropical convection, Clim. Dynam., 27, 787-813, doi:10.1007/s00382006-0158-0, 2006.

Jacob, H. and Sonntag, C.: An 8-year record of the seasonal variation of ${ }^{2} \mathrm{H}$ and ${ }^{18} \mathrm{O}$ in atmospheric water vapour and precipitation at heidelberg, Germany, Tellus B, 43, 291-300, 1991.

Jakobson, E., Vihma, T., Palo, T., Jakobson, L., Keernik, H., and Jaagus, J.: Validation of atmospheric reanalyses over the central arctic ocean, Geophys. Res. Lett., 39, L10802, doi:10.1029/2012gl051591, 2012.

Johnsen, S. J.: Stable isotope homogenization of polar firn and ice, in: Proc. Of symp. On isotopes and impurities in snow and ice, i.U.G.G. Xvi, general assembly, Grenoble August/September 1975, Iahs-aish publ. 118, Washington DC, 210-219, 1977.

Johnsen, S. J., Dansgaard, W., and White, J. W. C.: The origin of arctic precipitation under present and glacial conditions, Tellus B, 41, 452-468, 1989.

Johnsen, S. J., Clausen, H. B., Cuffey, K. M., Hoffmann, G., Schwander, J., and Creyts, T.: Diffusion of stable isotopes in polar firn and ice: The isotope effect in firn diffusion, in: Physics of ice core records, edited by: Hondoh, T., Hokkaido University Press, Sapporo, 121-140, 2000.

Joussaume, S., Jouzel, J., and Sadourny, R.: A general circulation model of water isotope cycles in the atmosphere, Nature, 311, 24-29, 1984.

Jouzel, J. and Merlivat, L.: Deuterium and oxygen 18 in precipitation: Modeling of the isotopic effects during snow formation, $\mathrm{J}$. Geophys. Res., 89, 11749-11757, 1984.

Kalnay, E., Kanamltsu, M., Kistler, R., Collins, W., Deaven, D., Gandin, L., Iredell, M., Saha, S., White, G., Woolle, J., Zhu, Y., Chelliah, M., Ebisuzaki, W., Higgins, W., Janowiak, J., Mo, K. C., Ropelewski, C., Wang, J., Leetmaa, A., Reynolds, R., Jenne, R., and Joseph, D.: The ncep/ncar 40-year reanalysis project, B. Am. Meteorol. Soc., 77, 437-471, 1996.

Kanamitsu, M., Ebisuzaki, W., Woollen, J., Yang, S. K., Hnilo, J. J., Fiorino, M., and Potter, G. L.: Ncep-doe amip-ii reanalysis (r-2), B. Am. Meteorol. Soc., 83, 1631-1643, doi:10.1175/bams83-11-1631, 2002.

Kavanaugh, J. L. and Cuffey, K. M.: Space and time variation of $\delta^{18} \mathrm{O}$ and $\delta \mathrm{D}$ in antarctic precipitation, revisited, Global Biogeochem. Cy., 17, 1017, doi:10.1029/2002GB001910, 2003.

Kerstel, E. R. T., van Trigt, R., Dam, N., Reuss, J., and Meijer, H. A. J.: Simultaneous determination of the ${ }^{2} \mathrm{H} /{ }^{1} \mathrm{H},{ }^{17} \mathrm{O} /{ }^{16} \mathrm{O}$, and ${ }^{18} \mathrm{O} /{ }^{16} \mathrm{O}$, isotope abundance ratios in water by means of laser spectrometry, Anal. Chem., 71, 5297-5303, 1999.

Koerner, R. M. and Fisher, D. A.: A record of holocene summer climate from a canadian high-arctic ice core, Nature, 343, 630631,1990

Kurita, N.: Origin of arctic water vapor during the ice-growth season, Geophys. Res. Lett., 38, L02709 doi:10.1029/2010g1046064, 2011.

Landais, A., Steen-Larsen, H. C., Guillevic, M., Masson-Delmotte, V., Vinther, B., and Winkler, R.: Triple isotopic composition of oxygen in surface snow and water vapor at neem (greenland), Geochim. Cosmochim. Ac., 77, 304-316, 2011.

Lee, X., Sargent, S., Smith, R., and Tanner, B.: In situ measurement of the water vapor o-18/o-16 isotope ratio for atmospheric and ecological applications,, J. Atmos. Ocean. Tech., 22, 1305-1305,
doi:10.1175/JTECH9001.1a, 2005.

Masson-Delmotte, V., Landais, A., Stievenard, M., Cattani, O., Falourd, S., Jouzel, J., Johnsen, S. J., Dahl-Jensen, D., Sveinbjornsdottir, A., White, J. W. C., Popp, T., and Fisher, H.: Holocene climatic changes in greenland: Different deuterium excess signals at greenland ice core project (grip) and northgrip, J. Geophys. Res., 110, D14102, doi:14110.11029/12004JD005575, 2005.

Masson-Delmotte, V., Braconnot, P., Hoffmann, G., Jouzel, J., Kageyama, M., Landais, A., Lejeune, Q., Risi, C., Sime, L., Sjolte, J., Swingedouw, D., and Vinther, B.: Sensitivity of interglacial Greenland temperature and $\delta^{18} \mathrm{O}$ : ice core data, orbital and increased $\mathrm{CO}_{2}$ climate simulations, Clim. Past, 7, 10411059, doi:10.5194/cp-7-1041-2011, 2011.

Merlivat, L. and Jouzel, J.: Global climatic interpretation of the deuterium-oxygen 18 relationship for precipitation, J. Geophys. Res., 84, 5029-5033, 1979.

Moon, T. K.: The expectation-maximization algorithm, Signal Processing Magazine, IEEE, 13, 47-60, 1996.

Persson, P. O. G., Fairall, C. W., Andreas, E. L., Guest, P. S., and Perovich, D. K.: Measurements near the atmospheric surface flux group tower at sheba: Near-surface conditions and surface energy budget, J. Geophys. Res., 107, 8045, doi:10.1029/2000jc000705, 2002.

Risi, C., Bony, S., Vimeux, F., and Jouzel, J.: Water stable isotopes in the $1 \mathrm{mdz} 4$ general circulation model: Model evaluation for present day and past climates and applications to climatic interpretations of tropical isotopic records, J. Geophys. Res., 115, D12118, doi:10.1029/2009JD013255, 2010a.

Risi, C., Landais, A., Bony, S., Jouzel, J., Masson-Delmotte, V., and Vimeux, F.: Understanding the o-17 excess glacial-interglacial variations in vostok precipitation, J. Geophys. Res.-Atmos., 115, doi:10.1029/2008jd011535, 2010b.

Risi, C., Bony, S., Vimeux, F., Frankenberg, C., Noone, D., and Worden, J.: Understanding the sahelian water budget through the isotopic composition of water vapor and precipitation, J. Geophys. Res., 115, D24110, doi:10.1029/2010jd014690, 2011.

Sime, L., Risi, C., Tindall, J. C., Sjolte, J., Wolff, E. W., Masson-Delmotte, V., and Capron, E.: Warm climate isotopic simulations: what do we learn about interglacial signals in Greenland ice cores?, Quaternary Sci. Rev., 67, 59-80, doi:10.1016/j.quascirev.2013.01.009, 2013

Simonsen, S. B., Johnsen, S. J., Popp, T. J., Vinther, B. M., Gkinis, V., and Steen-Larsen, H. C.: Past surface temperatures at the NorthGRIP drill site from the difference in firn diffusion of water isotopes, Clim. Past, 7, 1327-1335, doi:10.5194/cp-7-13272011, 2011.

Sjolte, J., Hoffmann, G., Johnsen, S. J., Vinther, B. M., MassonDelmotte, V., and Sturm, C.: Modeling the water isotopes in greenland precipitation 1959-2001 with the meso-scale model remo-iso, J. Geophys. Res.-Atmos., 116, D18105, doi:10.1029/2010jd015287, 2011.

Sodemann, H., Masson-Delmotte, V., Schwierz, C., Vinther, B. M., and Wernli, H.: Interannual variability of greenland winter precipitation sources: 2 . Effects of north atlantic oscillation variability on stable isotopes in precipitation, J. Geophys. Res.-Atmos., 113, D12111, doi:10.1029/2007jd009416, 2008.

Steen-Larsen, H. C., Masson-Delmotte, V., Sjolte, J., Johnsen, S. J., Vinther, B. M., Breon, F. M., Clausen, H. B., Dahl-Jensen, D., 
Falourd, S., Fettweis, X., Gallee, H., Jouzel, J., Kageyama, M., Lerche, H., Minster, B., Picard, G., Punge, H. J., Risi, C., Salas, D., Schwander, J., Steffen, K., Sveinbjornsdottir, A. E., Svensson, A., and White, J.: Understanding the climatic signal in the water stable isotope records from the neem shallow firn/ice cores in northwest greenland, J. Geophys. Res.-Atmos., 116, D06108, doi:10.1029/2010jd014311, 2011.

Steffen, K. and Box, J.: Surface climatology of the greenland ice sheet: Greenland climate network 1995-1999, J. Geophys. Res., 106, 33951-33964, 2001.

Steffen, K., Box, J. E., and Abdalati, W.: Greenland climate network: Gc-net, CRREL 96-27 Special Report on glaciers, Ice Sheets and Volcanoes, trib. to M. Meier, 98-103, 1996.

Stohl, A. and Seibert, P.: Accuracy of trajectories as determined from the conservation of meteorological tracers, Q. J. Roy. Meteor. Soc., 124, 1465-1484, doi:10.1256/smsqj.54906, 1998.

Stohl, A., Wotawa, G., Seibert, P., and Krompkolb, H.: Interpolation errors in wind fiels as a function of spatial and temporal resolution and their impact on different types of kinematic trajectories, Journal of Applied Meteorology, 34, 2149-2165, doi:10.1175/1520-0450(1995)034<2149:ieiwfa > 2.0.co;2, 1995.
Svensson, A., Andersen, K. K., Bigler, M., Clausen, H. B., DahlJensen, D., Davies, S. M., Johnsen, S. J., Muscheler, R., Rasmussen, S. O., Röthlisberger, R., Steffensen, J. P., and Vinther, B. M.: The greenland ice core chronology 2005, 15-42 kyr. Part 2: Comparison to other records, Quaternary Sci. Rev., 25, 32583267, 2006.

Thompson, D. W. J. and Wallace, J. M.: The arctic oscillation signature in the wintertime geopotential height and temperature fields, Geophys. Res. Lett., 25, 1297-1300, doi:10.1029/98g100950, 1998.

Worden, J., Bowman, K., Noone, D., Beer, R., Clough, S., Eldering, A., Fisher, B., Goldman, A., Gunson, M., Herman, R., Kulawik, S. S., Lampel, M., Luo, M., Osterman, G., Rinsland, C., Rodgers, C., Sander, S., Shephard, M., and Worden, H.: Tropospheric emission spectrometer observations of the tropospheric hdo/h(2)o ratio: Estimation approach and characterization, J. Geophys. Res.-Atmos., 111, D16309, doi:10.1029/2005jd006606, 2006. 